\title{
Mitral valve replacement in a patient with severe respiratory insufficiency
}

\author{
P. B. Wood ${ }^{1}$ and M. Paneth \\ From Brompton Hospital, London S.W.3
}

A case of successful mitral valve replacement is described in a 50-year-old man who had had a pneumonectomy for tuberculosis. The advances which allow mitral valve replacement to be offered to a wider selection of patients with mitral valvular dysfunction are considered.

The morbidity and mortality of valve replacement are both decreasing due to improvements in perfusion and operative techniques as well as in postoperative intensive care. We wish to record the successful replacement of the mitral valve in a patient with severe respiratory insufficiency and his subsequent considerable clinical improvement.

\section{Case Report}

A 50-year-old man had pulmonary tuberculosis when aged 24 in 1943 . He was treated initially with a left artificial pneumothorax and later (1950) with PAS and streptomycin. At this time a bronchogram showed that the whole of the left lung was bronchiectatic and a left pneumonectomy was performed. This was followed after some three months by a left thoracoplasty when the 2nd-6th ribs inclusive were removed.

He remained very well until 1967 when, over a ro-day period, he experienced progressive exertional dyspnoea with profound orthopnoea and was found to have developed a praecordial systolic murmur. His symptoms improved after digitalization. Right heart catheterization in September 1968 showed a pulmonary arterial wedge pressure, mean, of $26 \mathrm{mmHg}(\mathrm{a}=22$, $v=50, x=20, y=16$ ), a cardiac output of $2 \cdot 8$ $1 . / \mathrm{min}$, and right ventricular hypertension ( $55 / 4$ $\mathrm{mmHg}$ ). A diagnosis of mitral regurgitation was made. As his symptoms had improved on medical treatment he was kept under observation for the next two years, but his exercise tolerance gradually deteriorated and he developed 2-3 pillow orthopnoea. A chest $x$-ray at this time (Fig. I) showed old scarring and calcification in the right upper lobe, together with dilatation of the right pulmonary artery and proximal pulmonary vessels consistent with some degree of pulmonary hypertension. No assessment of heart size or shape could

\footnotetext{
1 Present address: Dept. of Thoracic Surgery, Toronto General Hospital, Canada.
}

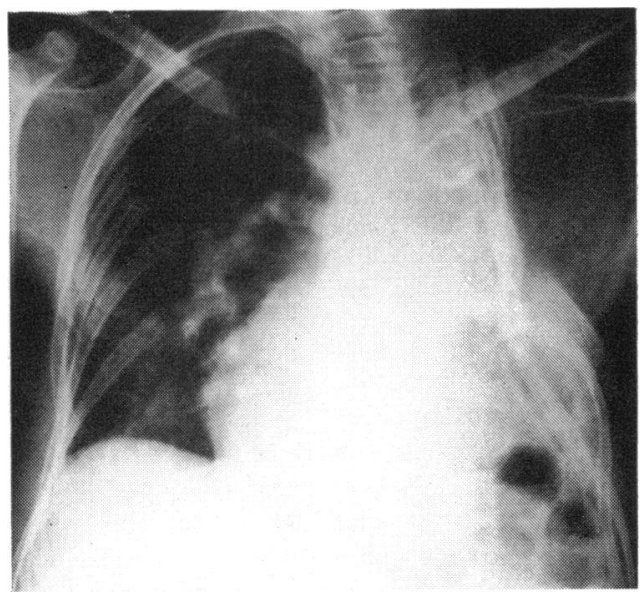

FIG. I Chest x-ray immediately before operation.

be made because of the left pneumonectomy and thoracoplasty. Lung function tests reflected the damage to his right lung in that the loss of lung volume and low transfer factor exceeded what would have been expected after a pneumonectomy. His lung volume (plethysmograph) was $1880 \mathrm{ml}$, vital capacity $1050 \mathrm{ml}$, and transfer factor for carbon monoxide at rest was $4.2 \mathrm{ml} \mathrm{CO} / \mathrm{min} /$ $\mathrm{mmHg}$. A vital capacity of $3880 \mathrm{ml}$ was predicted for a man of his height and weight and a transfer factor of $16.3 \mathrm{ml} \mathrm{CO} / \mathrm{min} / \mathrm{mmHg}$. Analysis of his arterial blood gasses showed the $\mathrm{P}_{\mathrm{A}} \mathrm{O}_{2}$ to be $58 \mathrm{mmHg}$ (normal approximately 90), $\mathrm{P}_{\mathrm{A}} \mathrm{CO}_{2}$ $55 \mathrm{mmHg}$ (normal approximately 40 ), and bicarbonate was $37 \mathrm{mEq} / \mathrm{l}$. (normal approximately 23).

After considerable discussion it was decided to offer the patient mitral valve replacement to which he readily consented. On 24 April 1970 on full bypass the mitral valve was exposed by the transseptal route (Brock, 1956) and the cause of the regurgitation was found to be rupture of the 


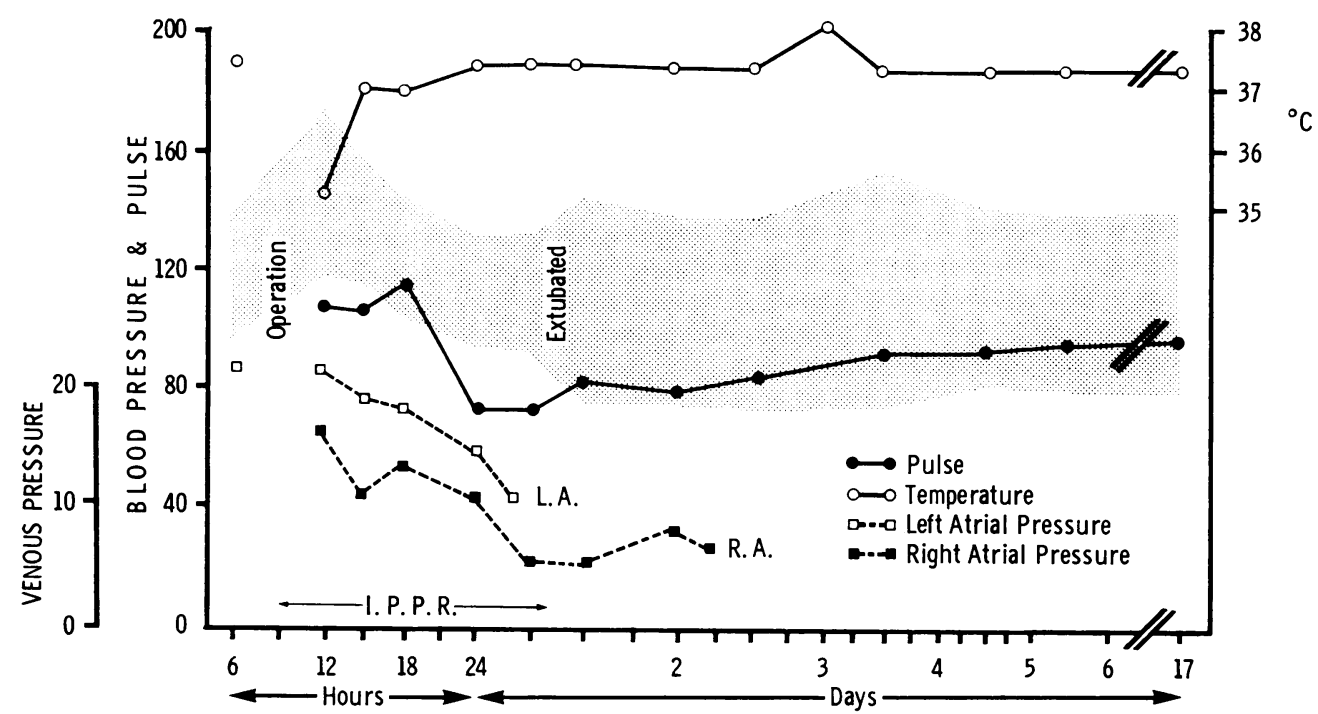

FIG. 2 Postoperative observations.

chordae controlling the posterior commissure, thus involving both leaflets. The valve was therefore replaced with a $2.4 \mathrm{~cm}$ aortic homograft mounted in a sleeve of Dacron which had been sterilized in antibiotics and preserved in carbon dioxide snow. The aorta had to be cross-clamped for one period of 43 minutes while the valve was inserted, to give adequate exposure.

Postoperatively he did very well and developed no respiratory problems (Fig. 2). He had one episode of mild congestive cardiac failure soon after operation, which was easily controlled with digoxin and diuretics. Now six months after his operation he feels better than at any time since the onset of chordal rupture. He has no signs or symptoms of cardiac failure and his chest $x$-ray shows diminution in congestion of pulmonary vessels.

\section{Discussion}

While it is probably still true to say that 'mitral valve replacement must continue to be performed only in patients who are so disabled that operation cannot reasonably be postponed' (Starr, Herr, and Wood, 1967), advances in the total management of such cases have meant that operation can be offered to a somewhat larger group of patients. Factors which may be important 'advances' include: (I) The ability to maintain high flows and a good arterial blood pressure on bypass; (2) increasing surgical skills which have led to a decrease in the time for which total heart/lung bypass is needed; (3) close monitoring of heart function postoperatively - particularly left and right atrial pressures which allow the postoperative fluid and drug regimen to be rigidly controlled; (4) the use of a period of postoperative intermittent positive pressure ventilation may provide valuable support to cardiovascular and respiratory function; (5) finally, it is our impression that the flow characteristics of aortic homografts lead to a smoother postoperative recovery. The long-term survival of these grafts in the mitral position is still to be determined.

\section{References}

Brock, R. (1956). The surgical approach to the left atrium: removal of an atrial myxoma. Guy's Hospital Reports, 105, 382.

Starr, A., Herr, R. H., and Wood, J. A. (1967). Mitral replacement. Review of six years' experience. fournal of Thoracic and Cardiovascular Surgery, 54, 333. 